\title{
Migratory Bone Marrow Edema Syndrome of the Hips: A Case Report
}

\author{
Santoso A, MD, Ingale PS*, MS Orth, Park KS*, PhD, Yoon TR*, PhD \\ Department of Orthopaedic and Traumatology, Sebelas Maret University, Solo, Indonesia \\ ${ }^{*}$ Center for Joint Disease, Chonnam National University Hwasun Hospital, Gwangju, Republic of Korea \\ This is an open-access article distributed under the terms of the Creative Commons Attribution License, which permits unrestricted use,
distribution, and reproduction in any medium, provided the original work is properly cited \\ Date of submission: 21st July 2017 \\ Date of acceptance: 30th September 2017
}

\begin{abstract}
Migratory bone marrow edema syndrome (BMES) of the hip is a rare entity. We report the case of a 41-year old male with migratory BMES of the hip with eight months interval period between onset of the pain and consultation. This patient was successfully treated non-surgically. It is important to always inform the patient with unilateral BMES of the hip regarding the possibility of future involvement of the contralateral hip.
\end{abstract}

Key Words:

bone marrow edema, hip joint, migratory

\section{INTRODUCTION}

Bone marrow edema syndrome (BMES) of the hip is an uncommon disease which is characterized by a self-limiting process $^{1}$. It primarily affects middle-aged men, and women during the last trimester of pregnancy ${ }^{1,2}$. BMES of the hip could present as a unilateral, simultaneous bilateral or a sequential/migratory case $^{3}$. The migratory case is rare. We present a patient with a migratory BMES of the hips in association with a short review of previous similar case reports.

\section{CASE REPORT}

A 41-year old male came to our outpatient clinic with a one month history of right inguinal pain. The pain was localized, non-radiating, aggravated by activity and relieved by rest. Visual analog scale (VAS) was 7-8. There was no history of pain in any other joint, history of trauma, alcohol abuse, steroid medication or other related illness. He was a physically fit person and worked as an office staff. His body weight was $78 \mathrm{~kg}$ and height $178 \mathrm{~cm}$ with body mass index $24.6 \mathrm{~kg} / \mathrm{m}^{2}$. On physical examination, there was a limping gait and positive on the Patrick's test of the right hip. The right hip range of motion was: flexion $90^{\circ}$, extension $10^{\circ}$, abduction $20^{\circ}$, adduction $20^{\circ}$, internal rotation $20^{\circ}$, and external rotation $30^{\circ}$. Examination of the rest of his body including the spine and contralateral hip was normal.

Laboratory study including hematology, biochemistry, coagulation, erythrocyte sedimentation rate and C-reactive protein revealed normal values. A pelvic anteroposterior radiograph showed mild osteopenia on the right femoral head and neck with joint space preserved. He had bilateral coxa valga with neck-shaft angle on the right of $145^{\circ}$ and left 145 (normal: 125-135 ${ }^{\circ}$ (Fig. 1). T2-weighted magnetic resonance imaging (MRI) showed high signal intensity which involved the right femoral head and neck with joint effusion (Fig. 2). Bone mineral density (BMD) examination with dual energy radiograph absorptiometry (DEXA) showed the total bone density of the hip was $1.014 \mathrm{~g} / \mathrm{cm}^{2}$ (Tscore 0.6, Z-Score 0.6). Bone scintigraphy (Tc-99m) examination revealed increased uptake on the right hip centered on the femoral head. A diagnosis of BMES was arrived at based on clinical and radiological findings. He was managed symptomatically with an advice to rest, partialweight bearing with crutch walking and analgesia for pain control (45mg of Pelubiprofen and a combination of 162, 5mg Acetaminophen $+18,75 \mathrm{mg}$ Tramadol) twice daily. Monthly radiographic examination during follow-up was planned. Clinical improvement was noticed at one month and subsequently the patient felt relieved of all symptoms.

About eight months after the initial onset, the patient visited our outpatient clinic complaining of a new onset of pain (VAS 6-7) on the opposite hip. He complained symptoms similar to that on his contralateral (right) hip previously. There was no history of significant event before onset of the recent pain. On physical examination of the right hip, there was no pain and range of motion of the hip was full. Physical

Corresponding Author: Taek-Rim Yoon, Department of Orthopaedic Surgery, Center for Joint Disease, Chonnam National University Hwasun Hospital, Gwangju, Republic of Korea

Email: tryoon@jnu.ac.kr 
Table I: Comparison with the previously reported cases of migratory BMES of the hip

\begin{tabular}{|c|c|c|c|c|c|}
\hline Authors & $\begin{array}{l}\text { Sex/Age } \\
\text { (years) }\end{array}$ & $\begin{array}{l}\text { Hip } \\
\text { migration }\end{array}$ & $\begin{array}{l}\text { Interval } \\
\text { period }\end{array}$ & $\begin{array}{l}\text { Possible } \\
\text { risk factors }\end{array}$ & Treatment \\
\hline Garzón G et al ${ }^{1}$ & $\mathrm{M} / 34$ & Right to left & 4 months & Unknown & Conservative therapy (?) \\
\hline Dhaliwal $\mathrm{J}$ et $\mathrm{al}^{2}$ & $\mathrm{M} / 20$ & Left to right & 6 months & $\begin{array}{l}\text { Hormonal therapy } \\
\text { due to hypothyroidism }\end{array}$ & Analgesia \\
\hline Iannò $\mathrm{B}$ et $\mathrm{al}^{3}$ & $\mathrm{M} / 44$ & Left to right & 12 years & $\begin{array}{l}\text { Repetitive trauma (left), } \\
\text { Unknown (right) }\end{array}$ & $\begin{array}{c}\text { Magnetotherapy + } \\
\text { Calcitonin Inj. (left)/ } \\
\text { Sodium Clodronate Inj. (right) + } \\
\text { non-weight bearing }\end{array}$ \\
\hline Yi SR et $\mathrm{al}^{4}$ & $M / 52$ & Right to left & 3 years & Unknown & $\begin{array}{c}\text { Analgesia + } \\
\text { limited physical activity }\end{array}$ \\
\hline Bolland $\mathrm{MJ}^{5}$ & $M / 32$ & Right to left & 6 months & $\begin{array}{l}\text { Carbamazepin } \\
\text { treatment due to epilepsy }\end{array}$ & Non-weight bearing \\
\hline Present case & $\mathrm{M} / 41$ & Right to left & 8 months & $\begin{array}{c}\text { Bilateral coxa } \\
\text { valga (?) }\end{array}$ & $\begin{array}{c}\text { Analgesia }+ \\
\text { partial-weight bearing }\end{array}$ \\
\hline
\end{tabular}

*M: Male, Inj: Injection

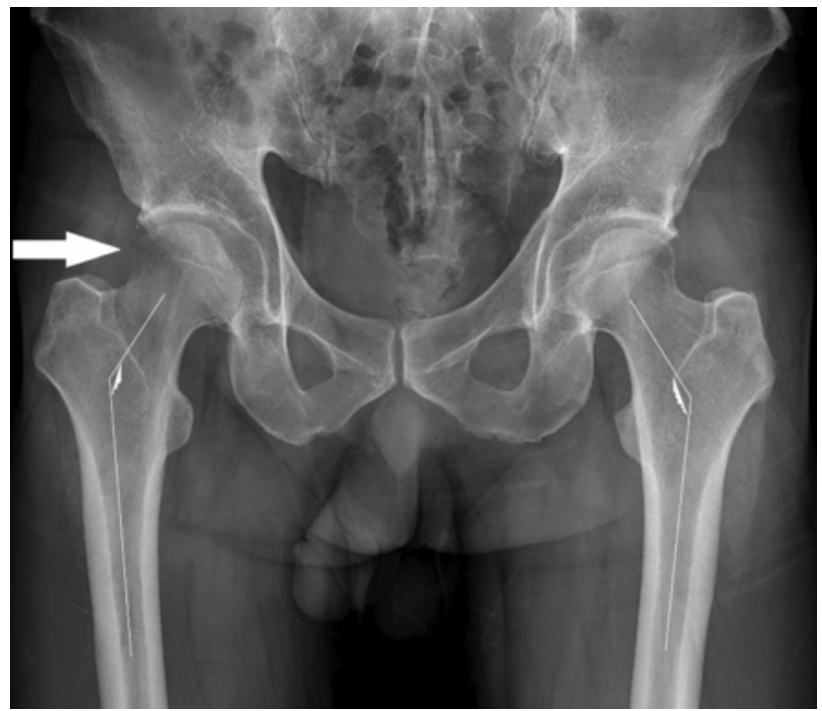

Fig. 1: Anteroposterior pelvic radiograph showing osteopenic bone on right femoral head and neck (white arrow). Valgus neck-shaft angle indicated by the lines.

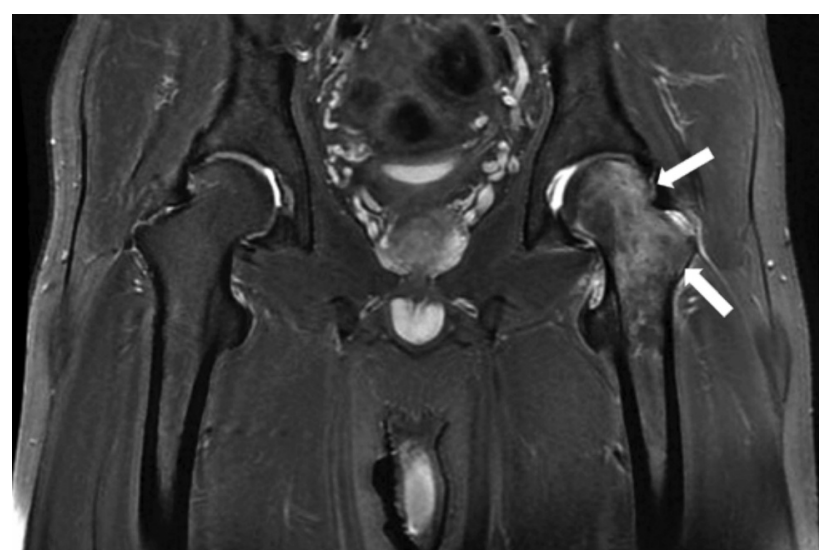

Fig. 3: T2-weighted MRI at the second onset left hip (8 month after first onset in right hip) showing high signal intensity on left femoral neck and head (white arrows) with normal signal intensity on right side.

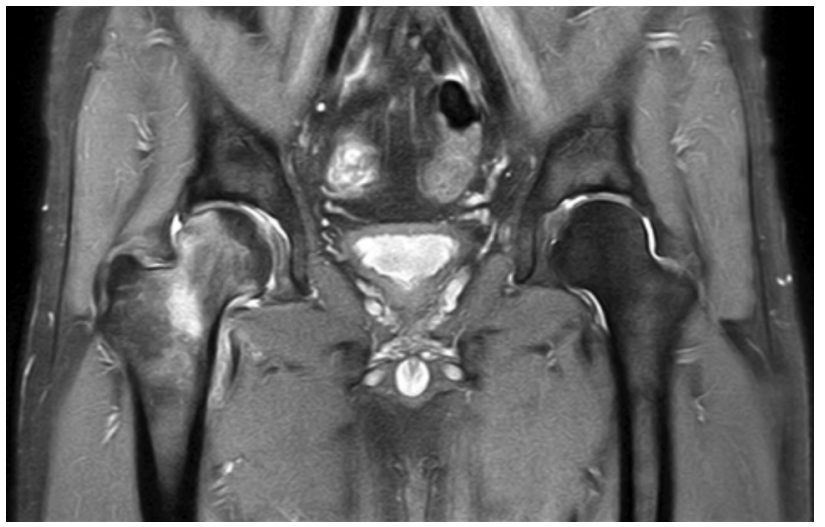

Fig. 2: T2-weighted MRI showing high signal intensity on right femoral neck and head along with joint effusion.

examination of the left hip revealed positive Patrick's test with limitation of range of motion. As before, laboratory examination revealed normal results. Pelvic anteroposterior radiograph showed slight osteopenic area on the left femoral head and neck. T2-weighted MRI showed high signal intensity on left femoral head and neck with normal intensity on the right side (Fig. 3). The total bone density was 1.019 $\mathrm{g} / \mathrm{cm}^{2}$ (T-score $0.6, \mathrm{Z}$-Score 0.6 ). At this second presentation, bone scintigraphy was not obtained. Due to similar clinical and image findings with previous contralateral right hip, we diagnosed this patient with having a migratory type of BMES of the left hip. Similar treatment protocol was instituted for the patient. Two months later pain had subsided and he had regained his normal activity level. He had no complaint on further follow-up at six months. Informed consent was obtained from the patient and his family for publication of this case report. 


\section{DISCUSSION}

We report migratory bone marrow edema syndrome of the hips occurring in a middle-aged male patient with less than a year of interval of onset between the two hips. Previously, several migratory BMES of the hip cases have been reported $^{1-5}$. Interestingly, all of them were of the male gender, with age range between 20 to 52 years. A wide range of the interval period between onset in both hips has been reported. The shortest interval was four months in a case reported by Garzon et $a l^{1}$, while the longest interval period was 12 years as recently reported in a case by Iannò et $a l^{3}$ (Table I).

Several risk factors have been proposed to be associated with BMES of the hip including: repetitive trauma, heavy lifting occupation, steroid intake, alcoholism and hormonal/ neurovascular problem associated with pregnancy ${ }^{2,3}$. One of the five previously reported cases had a history of hypothyroid state and had received thyroxin supplement ${ }^{2}$, while the other had a history of long term carbamazepine treatment $^{5}$. Our patient had bilateral coxa valga based on radiographic findings (neck-shaft angle $>135^{\circ}$ on both hips). Although a valgus hip is known to be associated with an increase in hip joint reaction force, its role as the risk factor for bone marrow edema syndrome remains unknown.
Symptomatic treatment remains the best choice for uncomplicated bilateral BMES of the hip. Treatment modalities from oral analgesic medication, oral/parenteral bisphosphonate, parenteral calcitonin to magnetotherapy have been reported ${ }^{3,4}$. The use of antiresorptive agent (bisphosphonate/calcitonin) is controversial, as osteoporosis was not always present in the BMES of the hip cases. Bone mineral density was within normal limit in our current case. Yi et $a l^{4}$ noted osteopenia of both hips on BMD measurement. Bolland ${ }^{5}$ reported an inconsistent finding with only one hip showing osteoporosis with the other one normal. Despite different result on BMD measurement, our present case and the case reported by Yi et $a l^{4}$ and Bolland ${ }^{5}$ were succesfully treated with only protected weight bearing or in combination with analgesic medication. The use of antiresorptive agent may be more beneficial for those who failed with symptomatic treatement and for those with a high risk of fracture ${ }^{5}$.

In summary, it is important to always warn the patient with a unilateral BMES of the hip on the possibility of future contralateral hip involvement. We hope this report, along with the short review of previously reported cases, may have some value in understanding the migratory pattern of BMES of the hip.

\section{CONFLICT OF INTEREST}

The authors have none to declare.

\section{REFERENCES}

1. Garzón JRG, Ramon J. CETIR Grup Medic. Consecutive bone scintigraphy in bilateral hip migratory transient osteoporosis. Clin Nucl Med. 2005; 30: 677-9.

2. Dhaliwal J, McConnell JS, Greer T. Bilateral transient osteoporosis of the hip in a 20-year-old man. BMJ Case Reports. 2014.

3. Iannò B, De Gori M, Familiari F, Pugliese T, Gasparini G. Transient osteoporosis of the hip with a contralateral delayed involvement: a case report. Clin Cases Miner Bone Metab. 2017; 14: 83-6.

4. Yi SR, Lee YH, Kim HM. Bilateral bone marrow edema syndrome of the femoral head with a unique onset: a case report. Hip Pelvis. 2015; 27: 273-7.

5. Bolland MJ. Bilateral transient osteoporosis of the hip in a young man. J Clin Densitom. 2008; 11(2): 339-41. 